Jāme e-šenāsī-e jāme'e-šenāsī dar İrān. Tehrān, Mo'asese-ye Našr-e Kalame, 1378/1999, 264 p. [La sociologie de la sociologie en Iran]

\title{
Mahmud Taleghani
}

\section{(2) OpenEdition}

1 Journals

\section{Édition électronique}

URL : http://journals.openedition.org/abstractairanica/37203

DOI : 10.4000/abstractairanica.37203

ISSN : 1961-960X

Éditeur :

CNRS (UMR 7528 Mondes iraniens et indiens), Éditions de l'IFRI

\section{Édition imprimée}

Date de publication : 15 mai 2001

ISSN : 0240-8910

\section{Référence électronique}

Mahmud Taleghani, « Jāme'e-šenāsīe jāme'e-šenāsī dar İrān. Tehrān, Mo'asese-ye Našr-e Kalame, 1378/1999, 264 p. [La sociologie de la sociologie en Iran] », Abstracta Iranica [En ligne], Volume 22 | 2001, document 585, mis en ligne le 17 février 2010, consulté le 12 octobre 2020. URL : http:// journals.openedition.org/abstractairanica/37203; DOI : https://doi.org/10.4000/abstractairanica 37203

Ce document a été généré automatiquement le 12 octobre 2020.

Tous droits réservés 


\title{
Jāme'e-šenāsī-e jāme'e-šenāsī dar İrān. Tehrān, Mo’asese-ye Našr-e Kalame, 1378/1999, 264 p. [La sociologie de la sociologie en Iran]
}

\author{
Mahmud Taleghani
}

1 Avec la publication de ce livre, un grand manque dans le domaine de la connaissance de la genèse et de l'évolution de la sociologie et de la pensée sociologique en Iran est rempli. L'auteur, dans une répartition judicieuse logique et exhaustive des sujets et des faits sociaux en dix chapitres, a traité les aspects de la pensée sociologique, les institutions, l'enseignement et la recherche sociologique et plus généralement les sciences sociales en Iran depuis le début du $20^{\mathrm{e}} \mathrm{s}$.

2 Le premier chapitre est consacré à l'étude des origines sociales, économiques et politiques affectant l'émergence de la sociologie en Iran; à ce propos l'influence des éléments de la modernité est soulignée.

Pour ce qui est des étapes de l'évolution et du développement de la sociologie, c'est le deuxième chapitre qui les reflète. Ici les fondateurs et la première génération des sociologues sont étudiés, ainsi que les premiers cours et ouvrages traduits ou rédigés. Parallèlement le Département de sociologie (plutôt des sciences sociales) de même que l'Institut d'Études et de Recherches Sociales (I.E.R.S.) de l'Université de Téhéran, fondés en 1957, sont passés en revue. Il est remarqué que la $2^{\mathrm{e}}$ génération des sociologues apparaît après la création de l'I.E.R.S. et du Département de sociologie. Pendant les années 1970 émergent les enseignants et les chercheurs de la $3^{\mathrm{e}}$ génération. La création de l'Association Iranienne de sociologie est également citée. Le $3^{e}$ chapitre est consacré à l'étude des spécificités de la sociologie en Iran. La littérature de cette science est, selon l'auteur, plutôt basée sur la traduction avec une tendance vers l'aspect théorique. Dans l'ensemble l'enseignement l'emporte sur la recherche et chaque branche est représentée par un leader et précurseur. La crise de la sociologie en Iran est le thème $\mathrm{du} 4^{\mathrm{e}}$ chapitre à travers lequel on apprend les racines de cette crise: pénurie de 
professeurs, manque de débouchés pour les diplômés en sociologie, pauvre contenu des ouvrages sociologiques en Iran et insuffisance de la méthodologie. Le $5^{\mathrm{e}}$ chapitre se penche sur les livres publiés (rédigés ou traduits) en ce domaine en Iran. Dans le $6^{\mathrm{e}}$ chapitre on passe en revue le contenu et les caractéristiques des articles publiés sur les problèmes sociaux. À travers le $7^{\mathrm{e}}$ chapitre on étudie les thèses et les mémoires des étudiants en sociologie et en sciences sociales, avec la répartition par sujet et par professeur-directeur ou conseiller ainsi que la répartition des espaces géographique et sociaux étudiés. Pour ce qui est de l'enseignement de la sociologie, c'est le chapitre 8 qui le traite à travers les différents niveaux universitaires. L'auteur remarque que les professeurs manquent d'innovation et d'initiative dans leur tâche d'enseignant et qu'un système d'évaluation de cet enseignement fait défaut.

$4 \quad$ Le $9^{\mathrm{e}}$ chapitre nous indique les principales tendances dans le domaine de la sociologie en Iran: côté théorique, côté étude de cas et description, sociologie de la société iranienne, sociologie islamique et ses différents aspects.

5 Enfin, le $10^{e}$ chapitre traite de l'avenir de la sociologie en Iran en mettant l'accent sur l'importance de l'institutionnalisation de la sociologie en Iran en rapport avec le cadre enseignant, les étudiants et les diplômés de cette science.

6 En guise de conclusion on peut affirmer que c'est très probablement la première fois qu'on arrive enfin à connaître, grâce à ce livre, les différentes facettes des problématiques de la sociologie en Iran, avec un regard analytique, concret et réaliste.

INDEX

Thèmes : 12.1. Iran

\section{AUTEURS}

MAHMUD TALEGHANI

INALCO - Paris 